\title{
Correction to: Variability in Tropical Cyclone Climatology over North Indian Ocean during the Period 1891 to 2015
}

\author{
Kasturi Singh ${ }^{1} \cdot$ Jagabandhu Panda $^{1}$ (D) Monalisa Sahoo ${ }^{2} \cdot$ M. Mohapatra $^{3}$
}

Published online: 20 February 2019

(C) Korean Meteorological Society and Springer Nature B.V. 2018

Correction to: Asia-Pac. J. Atmos. Sci. 2018

https://doi.org/10.1007/s13143-018-0069-0

Addition to 'Data and Methodology' section (i.e. section 2):

In the original version of this article, necessary details about the computation related to Mann-Kendall tau-b test was not given. The following paragraph may be added after the third paragraph of the 'Data and Methodology' section and may be referred as the second last paragraph of the section 2 .

The Mann-Kendall tau-b is computed according to the following formulation:

Tau $b=S / D$.

The parameters, 'S' and ' $\mathrm{D}$ ' can be computed by considering a set of observations ' $\left(\mathrm{X}_{1}, \mathrm{Y}_{1}\right),\left(\mathrm{X}_{2}, \mathrm{Y}_{2}\right) \ldots . .\left(\mathrm{X}_{\mathrm{n}}, \mathrm{Y}_{\mathrm{n}}\right)$ ' of joint random variables $\mathrm{X}$ and $\mathrm{Y}$. For a given pair of ranks $\mathrm{Xi}$ and $\mathrm{Xj}$ (where $\mathrm{i}<\mathrm{j}$ ), a score of ' +1 ' is assigned if $\mathrm{Xi}<\mathrm{Xj},{ }^{\prime}-1$ ' is assigned if $\mathrm{Xi}>\mathrm{Xj}$. and ' 0 ' is assigned if $\mathrm{Xi}=\mathrm{Xj}$. The statistic ' $\mathrm{S}$ ' is then obtained by summing the products of the resulting scores for each corresponding pair of ranks in the two distributions:

$S=\sum_{i=1}^{n-1} \sum_{j=i+1}^{n}\left[\operatorname{sgn}\left(\mathrm{X}_{j}-\mathrm{X}_{i}\right) \operatorname{sgn}\left(\mathrm{Y}_{\mathrm{j}}-\mathrm{Y}_{\mathrm{i}}\right)\right]$

The online version of the original article can be found at https://doi.org/ 10.1007/s13143-018-0069-0

Jagabandhu Panda

pandaj@nitrkl.ac.in; jagabandhu@gmail.com

1 Department of Earth and Atmospheric Sciences, National Institute of Technology Rourkela, Odisha 769008, India

2 Indian Institute of Tropical Meteorology, Dr. Homi Bhabha Road, Pashan, Pune, Maharashtra 411008, India

3 Cyclone Warning Division, India Meteorological Department, Mausam Bhavan, Lodi Road, New Delhi 110003, India where

$\operatorname{sgn}\left(\mathrm{Xj}_{-} \mathrm{Xi}\right)=\left\{\begin{array}{c}1, \text { if } X_{i}<X_{j} \\ 0, \text { if } X_{i}=X_{j} \\ -1, \text { if } X_{i}>X_{j}\end{array}\right.$
$\operatorname{sgn}(\mathrm{Yj}-\mathrm{Yi})=\left\{\begin{array}{c}1, \text { if } Y_{i}<Y_{j} \\ 0, \text { if } Y_{i}=Y_{j} \\ -1, \text { if } Y_{i}>Y_{j}\end{array}\right.$

Similarly, 'D' can be computed as:

$\mathrm{D}=\sqrt{\left[\frac{n(n-1)}{2}-\sum_{i=1}^{t} \frac{t_{i}\left(t_{i}-1\right)}{2}\right]} \sqrt{\left[\frac{n(n-1)}{2}-\sum_{i=1}^{u} \frac{u_{i}\left(u_{i}-1\right)}{2}\right]}$

The total number of possible pairings of ' $\mathrm{X}$ ' with ' $\mathrm{Y}$ ' observations is $\mathrm{n}(\mathrm{n}-1) / 2$. Here, $t_{i}$ is the number of observations tied at a particular rank of ' $\mathrm{X}$ ' and $u_{i}$ is the number tied at a rank of ' $Y$ '. In the current study, ' $X$ ' represents years and ' $Y$ ' represents the variables considered.

\section{Addition to 'Determination of Warming Period' section (i.e. section 3):}

The following sentence may be added at the end of the second paragraph of section 3 :

"Further, it may be noted that the methodology for determination of PWP and CWP primarily adopted by following Mohanty et al. (2012) and Singh et al. (2018).”

\section{Addition to 'Concluding Remarks' section (i.e. section 6):}

The following statements may be considered in continuity as part of the last paragraph of the section 6:

"Further, one of the limiting factors in this study realised as the basis of consideration of PWP and CWP based on SST 
anomaly variation. In the PWP, there are few years during 1940-1946, which show appreciable positive anomaly. Similarly, during the early CWP i.e. 1947-1956, there are appreciable negative SST anomalies too. Thus, considering CWP from 1957, if the results are analysed, majority of the findings would remain unchanged except the statistics part. Therefore, the conclusions drawn in this study may be considered accordingly."

\section{References}

Mohanty, U.C., Osuri, K.K., Pattanayak, S., Sinha, P.: An observational perspective on tropical cyclone activity over Indian seas in a warming environment. Nat. Hazards. 63, 1319-1335 (2012)

Singh, K., Panda, J., Rath, S.S.: Variability in landfalling trends of cyclonic disturbances over North Indian Ocean region during current and pre-warming climate. Theor. Appl. Climatol. (2018). https://doi. org/10.1007/s00704-018-2605-3 